\title{
Hierarchically Structured Metal Oxide/Silica Nanofibers by Colloid Electrospinning
}

\author{
Nesrin Horzum, ${ }^{\dagger, \dagger}$ Rafael Muñoz-Espí, ${ }^{\dagger}$ Gunnar Glasser, ${ }^{\dagger}$ Mustafa M. Demir, ${ }^{\ddagger}{ }^{\S}$ Katharina Landfester, ${ }^{\dagger}$ \\ and Daniel Crespy* $\dagger$

\begin{abstract}
${ }^{\dagger}$ Max Planck Institute for Polymer Research, Ackermannweg 10, 55128 Mainz, Germany
${ }^{\ddagger}$ Department of Chemistry, and ${ }^{\S}$ Material Science and Engineering Program, Izmir Institute of Technology, Urla, 35430, İzmir, Turkey
\end{abstract}

\begin{abstract}
We present herein a new concept for the preparation of nanofibrous metal oxides based on the simultaneous electrospinning of metal oxide precursors and silica nanoparticles. Precursor fibers are prepared by electrospinning silica nanoparticles (20 $\mathrm{nm}$ in diameter) dispersed in an aqueous solution of poly(acrylic acid) and metal salts. Upon calcination in air, the poly(acrylic acid) matrix is removed, the silica nanoparticles are cemented, and nanocrystalline metal oxide particles of $4-14 \mathrm{~nm}$ are nucleated at the surface of the silica nanoparticles. The obtained continuous silica fibers act as

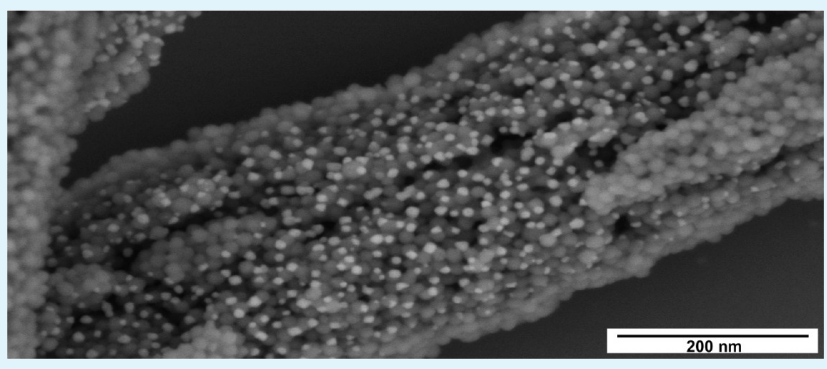
a structural framework for metal oxide nanoparticles and show improved mechanical integrity compared to the neat metal oxide fibers. The hierarchically nanostructured materials are promising for catalysis applications, as demonstrated by the successful degradation of a model dye in the presence of the fibers.
\end{abstract}

KEYWORDS: catalysis, ceria, electrospinning, lithium cobalt oxide, metal oxide, nanoparticles

\section{INTRODUCTION}

Because of their large ratio of surface area to volume and interconnected porosity, metal oxide meshes have been proposed for applications in catalysis, energy storage, and sensors. ${ }^{1-3}$ Various bottom-up approaches- such as vaporliquid-solid (VLS) ${ }^{4}$ and vapor-solid (VS) ${ }^{5}$ growth-and topdown techniques- such as nanocarving ${ }^{6}$ and electrospinning ${ }^{7}$ - have been described. Among these techniques, electrospinning is probably the most versatile, because it allows the fabrication of fibrous mats from a wide variety of both organic and/or inorganic materials. ${ }^{8,9}$ Moreover, it allows for control over the diameter, morphology, porosity, alignment, and composition of the resulting fibers. ${ }^{10,11}$

Calcination of electrospun mats obtained from metal oxide precursors is a commonly used approach because of its facility and potential for upscaling. The calcination process is usually applied to mixtures of polymers/metal oxide precursors and it is based on an oxidative conversion of the polymeric component by heat treatment. There are many successful examples in literature for the fabrication of inorganic fibers by calcination of precursor materials prepared by sol-gel, ${ }^{12-18}$ polymer-based sol-gel processes, ${ }^{19-22}$ or from electrospinning of polymer dispersions in the presence of ex situ formed colloids. ${ }^{23-27}$ Upon increase of the temperature, metal oxide crystals nucleate and grow while the polymeric component undergoes degradation. $^{28,29}$

In the electrospinning of inorganic precursor, one has to take into account that the calcination leads almost automatically to a shrinkage of the fibers because the polymer template is removed. After calcination, the nanofibers are usually more brittle ${ }^{30}$ because of their thinner section and the internal stress generated by the shrinkage. Therefore, an additional material that is not mechanically or chemically affected by the calcination process needs to be incorporated in the fibers during the electrospinning.

The recently reviewed electrospinning of colloids ${ }^{31}$ has been explored for the fabrication of metal or metalloid oxide fibers. For instance, silica ${ }^{24,26}$ and titania $^{32}$ nanoparticles were embedded in polymer fibers by electrospinning a solution of polymer template in the presence of a dispersion of the particles. Recently, the electrospinning of a zinc powder/ titanium isopropoxide/poly(vinyl acetate) mixture was reported. ${ }^{33}$ The precursor fibers were calcinated in air and the subsequent hydrothermal treatment of the resulting fibers in bis(hexamethylene)triamine and a zinc nitrate hexahydrate solution yielded continuous $\mathrm{TiO}_{2}$ fibers decorated with $\mathrm{ZnO}$ branches. The $\mathrm{ZnO}$ particles in the $\mathrm{TiO}_{2}$ fibers seeded the growth of $\mathrm{ZnO}$ branches perpendicular to the $\mathrm{TiO}_{2}$ fibers direction. The same procedure was employed to form $\mathrm{ZnO}$ branched $\mathrm{Co}_{3} \mathrm{O}_{4}{ }^{34}$ and $\mathrm{ZnO}$-branched $\mathrm{ZnO}^{35}$ fibers. Although the synthesis of silica-supported metal oxide nanocomposites has been previously reported, ${ }^{36-38}$ their fabrication by colloidelectrospinning to obtain nanofibers is a new strategy. Our concept allows the advantageous combination of interesting

Received: September 12, 2012

Accepted: October 23, 2012

Published: October 23, 2012 
properties inherent to both nanoparticles (high surface area) and meshes (porous structure and facile separation from the reaction media). Furthermore, the incorporation of silica nanoparticles in the composite fibers significantly improves the mechanical integrity of the nanofibers. The generality of the concept is demonstrated by taking two different metal oxides, namely $\mathrm{CeO}_{2}$ and $\mathrm{LiCoO}_{2}$ as models for simple and binary oxides, respectively. The catalytic activity of the composite nanofibers was also investigated.

\section{EXPERIMENTAL SECTION}

Materials. Cerium(III) nitrate hexahydrate (Fluka, $\geq 99.0 \%$ ), lithium hydroxide (Aldrich, 98\%), cobalt(II) hydroxide (Aldrich, 95\%), poly(acrylic acid) (PAA, $M_{\mathrm{w}} \approx 450000 \mathrm{~g} \mathrm{~mol}^{-1}$, Polysciences Inc.), colloidal silica (average diameter: $20 \mathrm{~nm}$, BET surface area: 140 $\mathrm{m}^{2} \mathrm{~g}^{-1}, 34 \mathrm{wt} \%$ suspension in $\mathrm{H}_{2} \mathrm{O}$, Sigma-Aldrich), and rhodamine B (Merck) were all used as received without any further purification. Demineralized water was used throughout the study.

Preparation of the Electrospinning Solutions. The metal salt(s), $\mathrm{Ce}\left(\mathrm{NO}_{3}\right)_{3} \cdot 6 \mathrm{H}_{2} \mathrm{O}(780 \mathrm{mg}, 1.8 \mathrm{mmol}$; and $390 \mathrm{mg}, 0.9 \mathrm{mmol})$ or $\mathrm{LiOH}(21.5 \mathrm{mg}, 0.9 \mathrm{mmol})$ and $\mathrm{Co}(\mathrm{OH})_{2}(83 \mathrm{mg}, 0.90 \mathrm{mmol})$, were added to a $7.5 \mathrm{wt} \%$ solution of PAA $(0.870 \mathrm{~g})$, and the mixture was stirred for $2 \mathrm{~h}$ at room temperature.

For the fabrication of metal oxide/silica fibers, the colloidal silica was dispersed in $4.0 \mathrm{~g}$ of the PAA/metal salt solution. The weight ratio of PAA: $\mathrm{SiO}_{2}$ was fixed as $1: 1$. Two different $\mathrm{Ce}\left(\mathrm{NO}_{3}\right)_{3} \cdot 6 \mathrm{H}_{2} \mathrm{O}$ concentrations with respect to the amount of silica (mole ratios $\mathrm{Ce}: \mathrm{Si}$ ) were used: $0.06: 1.00$ and $0.12: 1.00$ (mole ratios).

Fabrication of the Nanofibers. The viscous solutions of PAA/ metal salt precursor or the dispersions of PAA/metal salt precursor/ $\mathrm{SiO}_{2}$ were loaded in a plastic syringe connected with silicon rubber tubing. The electrospinning experiments were carried out with a commercial platform (ES1a, Electrospinz) covered with a polycarbonate box placed for safety and to avoid disturbances from air convection. The positive electrode was applied to the spinneret and an aluminum foil was used as counter electrode. The flow rate of the polymer solution was adjusted by a syringe pump (Bioblock, $K_{\mathrm{d}}$ Scientific). The optimum electrospinning parameters are presented in Table 1. PAA $/ \mathrm{SiO}_{2}, \mathrm{PAA} / \mathrm{SiO}_{2} / \mathrm{Ce}\left(\mathrm{NO}_{3}\right)_{3}, \mathrm{PAA} / \mathrm{Ce}\left(\mathrm{NO}_{3}\right)_{3}$, and

Table 1. Optimized Electrospinning Parameters (tip-tocollector distance fixed at $14 \mathrm{~cm}$ )

\begin{tabular}{llcc} 
metal oxide & \multicolumn{1}{c}{ precursor } & $\begin{array}{c}\text { electric field } \\
\left.(\mathrm{kV} \mathrm{cm})^{-1}\right)\end{array}$ & $\begin{array}{c}\text { flow rate } \\
\left(\mathrm{mL} \mathrm{h}^{-1}\right)\end{array}$ \\
$\mathrm{CeO}_{2}$ & $\mathrm{PAA} / \mathrm{Ce}\left(\mathrm{NO}_{3}\right)_{3} \cdot 6 \mathrm{H}_{2} \mathrm{O}$ & 0.71 & 2 \\
$\mathrm{CeO}_{2} / \mathrm{SiO}_{2}$ & $\mathrm{PAA} / \mathrm{Ce}\left(\mathrm{NO}_{3}\right)_{3} \cdot 6 \mathrm{H}_{2} \mathrm{O} /$ & 0.71 & 2 \\
& $\mathrm{SiO}_{2}$ & & 1 \\
$\mathrm{SiO}_{2}$ & $\mathrm{PAA} / \mathrm{SiO}_{2}$ & 0.36 & 2 \\
$\mathrm{LiCoO}_{2}$ & $\mathrm{PAA} / \mathrm{LiOH} / \mathrm{Co}(\mathrm{OH})_{2}$ & 1.43 & 1 \\
$\mathrm{LiCoO}_{2} /$ & $\mathrm{PAA} / \mathrm{LiOH} / \mathrm{Co}(\mathrm{OH})_{2} /$ & 0.71 & \\
$\mathrm{SiO}_{2}$ & $\mathrm{SiO}$ & & \\
\hline
\end{tabular}

$\mathrm{PAA} / \mathrm{SiO}_{2} / \mathrm{LiOH} / \mathrm{Co}(\mathrm{OH})_{2}$ fibers were calcinated under air in a muffle oven (Nabertherm Controller P330 LT 5/13) at $600{ }^{\circ} \mathrm{C}$ (room temperature to $600{ }^{\circ} \mathrm{C}$ at a rate of $4{ }^{\circ} \mathrm{C} \mathrm{min}^{-1}$; plateau of $2 \mathrm{~h}$ at 600 $\left.{ }^{\circ} \mathrm{C}\right)$. PAA $/ \mathrm{LiOH} / \mathrm{Co}(\mathrm{OH})_{2}$ fibers were calcinated at $400{ }^{\circ} \mathrm{C}$ for $5 \mathrm{~h}$ with a rate of $4{ }^{\circ} \mathrm{C} \mathrm{min}^{-1}$.

Characterization Methods. The fibers were electrospun onto silicon wafers for morphological observations by scanning electron microscopy (SEM) in a LEO 1530 Gemini microscope (Zeiss). To localize the metal oxide nanoparticles on the fibers, high-resolution SEM micrographs were captured using a Hitachi SU8000 microscope. The diameter of fibers and particle size distributions were calculated from SEM micrographs by using the software Fiji/ImageJ. X-ray diffraction pattern (XRD) were recorded in a Philips PW 1820 diffractometer using $\mathrm{Cu}_{\mathrm{K} \alpha}$ radiation $(\lambda=1.5418 \AA)$. Thermogravimetric analysis (TGA) was studied by a Mettler Toledo 851 thermobalance. The specific surface area of the calcinated fibers was determined from nitrogen adsorption using a Micromeritics Gemini V instrument. The surface area was calculated according to the Brunauer-Emmett-Teller (BET) methodology (five point, $0.05<$ $\left.P / P_{0}<0.3\right)$. The samples were degassed at $400{ }^{\circ} \mathrm{C}$ for $6 \mathrm{~h}$ in vacuum prior to the measurements.

The photocatalytic degradation of rhodamine $\mathrm{B}$ (Merck) in the presence of pure $\mathrm{CeO}_{2}, \mathrm{CeO}_{2} / \mathrm{SiO}_{2}$, and $\mathrm{SiO}_{2}$ fibers was carried out in a polystyrene plate (Corning) under UV light irradiation. For the catalysis experiments, the fiber catalyst $(2.0 \mathrm{mg})$ was added to an aqueous solution of rhodamine $\mathrm{B}(1.5 \mathrm{~mL}, 5 \mathrm{ppm})$ and stirred continuously. At certain time intervals, photoluminescence (PL) emission spectra of the dye solution with the fiber mats were registered in top-mode on a Tecan Infinite M100 plate reader using an excitation wavelength of $500 \mathrm{~nm}$.

\section{RESULTS AND DISCUSSION}

The preparation of silica-supported metal oxide fibers by colloid electrospinning and subsequent controlled thermal treatment is presented for two systems: $\mathrm{CeO}_{2}$, as a model for a simple metal oxide, and $\mathrm{LiCoO}_{2}$, as a model for a binary system. Silica nanoparticles were selected as cheap but robust structural framework for the final materials. Initially, poly(acrylic acid) (PAA) and a metal salt (either $\mathrm{Ce}\left(\mathrm{NO}_{3}\right)_{3} \cdot 6 \mathrm{H}_{2} \mathrm{O}$ or $\mathrm{LiOH}$ and $\left.\mathrm{Co}(\mathrm{OH})_{2}\right)$ were dissolved in water, and the homogeneous aqueous polymer solution was electrospun. In a second step, the resulting mats were converted to metal oxide fibers by thermal treatment in a controlled environment. A schematic diagram for the fabrication of metal oxide and metal oxide/silica fibers is depicted in Figure 1. In both systems, PAA was used as polymer template and binder in the fibers. PAA is a commonly used polyelectrolyte, with most of the carboxyl groups being deprotonated at neutral $\mathrm{pH}\left(\mathrm{pK}_{\mathrm{a}} 4-4.5\right),{ }^{39}$ which provide the ability to coordinate metal cations.

The thermal decomposition of $\mathrm{PAA} / \mathrm{SiO}_{2}$ fibers measured by thermogravimetric analysis (TGA) showed two consecutive mass losses (Figure 2a), attributed to the elimination of adsorbed water, and to the degradation of poly(acrylic acid).$^{40}$ The three weight losses observed for the PAA/Ce $\left(\mathrm{NO}_{3}\right)_{3}$ and $\mathrm{PAA} / \mathrm{Ce}\left(\mathrm{NO}_{3}\right)_{3} / \mathrm{SiO}_{2}$ fibers are consecutive to the elimination of adsorbed water, the dehydration of cerium nitrate and degradation of PAA, and the conversion of anhydrous $\mathrm{Ce}\left(\mathrm{NO}_{3}\right)_{3}$ to $\mathrm{CeO}_{2}$ (at increasing temperature). ${ }^{41}$ Since the mass of the materials remains unchanged around $600{ }^{\circ} \mathrm{C}$, the calcination temperature was fixed at this temperature. After calcination, the majority of the remaining residue is expected to be composed of $\mathrm{CeO}_{2}$ and/or $\mathrm{SiO}_{2}$. Experimentally measured and theoretical percentages of remaining residues, calculated from the initially introduced precursor assuming complete conversion to $\mathrm{CeO}_{2}$, are listed in Table 2 . In the presence of $\mathrm{SiO}_{2}$ nanoparticles, the remaining material after calcination of $\mathrm{PAA} / \mathrm{SiO}_{2}$ fibers was higher (48\%) than that of PAA/ $\mathrm{Ce}\left(\mathrm{NO}_{3}\right)_{3}$ fibers (23\%). The thermal stability of the fibers was slightly increased upon addition of $\mathrm{SiO}_{2}$ nanoparticles with an onset of degradation temperature shifted to more than 15 ${ }^{\circ} \mathrm{C}$ in the presence of silica particles.

Similarly, the thermal decomposition of the PAA/LiOH/ $\mathrm{Co}(\mathrm{OH})_{2}$ fibers occurs in three stages in the temperature range of $25-720{ }^{\circ} \mathrm{C}$ (Figure $2 \mathrm{~b}$ ). The weight losses were ascribed to the removal of adsorbed water $(\sim 10 \%)$, the polymer degradation and the conversion of $\mathrm{Co}(\mathrm{OH})_{2}$ to $\mathrm{Co}_{3} \mathrm{O}_{4}$ $(56 \%),{ }^{42}$ and the reaction of $\mathrm{Co}_{3} \mathrm{O}_{4}$ with the lithium salt to form $\mathrm{LiCoO}_{2} \cdot{ }^{43}$ Similar to the aforementioned results obtained for $\mathrm{CeO}_{2}$, the addition of $\mathrm{SiO}_{2}$ nanoparticles shifted the 

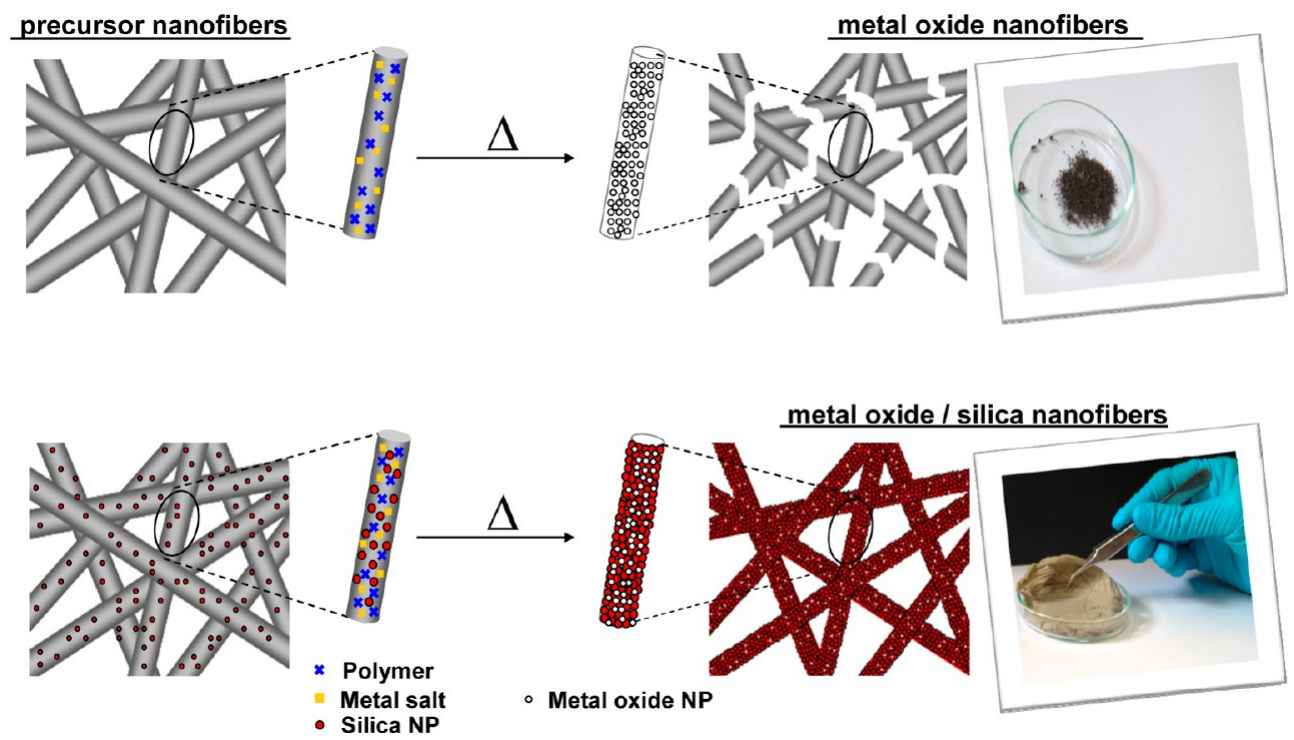

Figure 1. Scheme of the preparation of metal oxide (top) and metal oxide/silica (bottom) fibers. The metal oxide fiber are brittle and yield a powder material, whereas the nanofibrous morphology is conserved by using silica nanoparticles as structural framework.
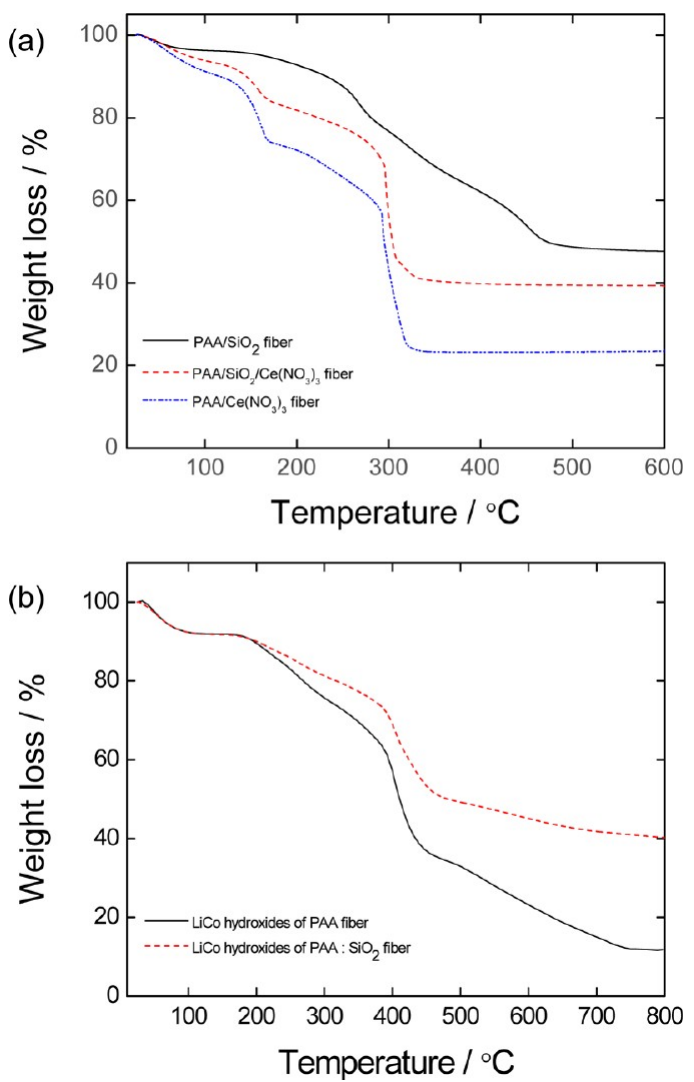

Figure 2. TGA thermograms of (a) $\mathrm{PAA} / \mathrm{SiO}_{2} / \mathrm{Ce}\left(\mathrm{NO}_{3}\right)_{3}$ and $\mathrm{PAA} /$ $\mathrm{Ce}\left(\mathrm{NO}_{3}\right)_{3}$ fibers, and (b) $\mathrm{PAA} / \mathrm{LiOH} / \mathrm{Co}(\mathrm{OH})_{2}, \mathrm{PAA} / \mathrm{SiO}_{2} / \mathrm{LiOH} /$ $\mathrm{Co}(\mathrm{OH})_{2}$ fibers.

decomposition temperature to higher values. Indeed, the remaining mass at $600{ }^{\circ} \mathrm{C}$ for the PAA/LiCo hydroxide fibers was $23 \%$ versus $45 \%$ in the presence of 6.5 wt $\%$ of $\mathrm{SiO}_{2}$. Since the degradation mechanism relies generally on the diffusion of polymer residues formed upon increase of temperature, the nanoparticles may act as barrier for mass transport, hence improving the thermal properties of the materials. Such phenomenon was already reported by Mizuno et al., ${ }^{44}$ who
Table 2. Diameters of the Fibers and Percent Compositions of the Metal Oxide/Silica Fibers

\begin{tabular}{|c|c|c|c|c|c|}
\hline fiber & $\begin{array}{c}d_{\text {fiber }} \text { before } \\
\text { calcination } \\
(\mathrm{nm})\end{array}$ & $\begin{array}{l}d_{\text {fiber }} \text { after } \\
\text { calcination } \\
(\mathrm{nm})\end{array}$ & $\begin{array}{l}\mathrm{CeO}_{2}{ }^{b} \\
(\mathrm{vol} \%)\end{array}$ & $\begin{array}{c}\mathrm{CeO}_{2}{ }^{+} \\
\mathrm{SiO}_{2} \mathrm{c}^{\mathrm{c}} \\
(\mathrm{wt} \%)\end{array}$ & $\begin{array}{c}\mathrm{CeO}_{2}+ \\
\mathrm{SiO}_{2}^{d} \\
(\text { wt \%) }\end{array}$ \\
\hline $\mathrm{SiO}_{2}$ & $540 \pm 80$ & $510 \pm 80$ & & 48 & 50 \\
\hline $\begin{array}{c}\mathrm{CeO}_{2} / \mathrm{SiO}_{2} \\
(0.06 / 1.00)\end{array}$ & $290 \pm 50$ & $180 \pm 30$ & 6.3 & 40 & 48 \\
\hline $\begin{array}{c}\mathrm{CeO}_{2} / \mathrm{SiO}_{2} \\
(0.12 / 1.00)\end{array}$ & $300 \pm 40$ & $190 \pm 30$ & 12.2 & 33 & 47 \\
\hline $\mathrm{CeO}_{2}$ & $320 \pm 50$ & $240 \pm 40$ & 100.0 & 23 & 19 \\
\hline fiber & $\begin{array}{c}d_{\text {fiber }} \text { before } \\
\text { calcination } \\
(\mathrm{nm})\end{array}$ & $\begin{array}{c}d_{\text {fiber }} \text { after } \\
\text { calcination } \\
(\mathrm{nm})\end{array}$ & $\begin{array}{c}\mathrm{LiCoO}_{2}{ }^{b} \\
(\text { vol \%) }\end{array}$ & $\begin{array}{l}\mathrm{LiCoO}_{2} \\
+\mathrm{SiO}_{2}{ }^{\mathrm{c}} \\
\text { (wt \%) }\end{array}$ & $\begin{array}{l}\mathrm{LiCoO}_{2} \\
+\mathrm{SiO}_{2}{ }^{\mathrm{a}} \\
\text { (wt \%) }\end{array}$ \\
\hline $\mathrm{LiCoO}_{2}$ & $310 \pm 60$ & $190 \pm 30$ & 100.0 & 12 & 18 \\
\hline $\begin{array}{c}\mathrm{LiCoO}_{2} / \\
\mathrm{SiO}_{2}\end{array}$ & $350 \pm 80$ & $320 \pm 100$ & 5.03 & 41 & 57 \\
\hline
\end{tabular}

${ }^{a}$ Measured with SEM. ${ }^{b}$ Calculated from eq $2 .{ }^{c}$ Measured with TGA. $d_{\text {Theoretical content. }}$

found that the presence of vapor-grown carbon fiber hindered the decomposition of PVA.

The obtained electrospun materials were observed by SEM before (Figure $3 \mathrm{a}-\mathrm{d}$ ) and after calcination (Figure $3 \mathrm{e}-\mathrm{h}$ ). Fiber mats prepared from PAA solutions with different $\mathrm{Ce} / \mathrm{Si}$ mole ratios (0.06 and 0.12) were compared with references prepared from PAA solutions containing only either $\mathrm{Ce}\left(\mathrm{NO}_{3}\right)_{3}$ or $\mathrm{SiO}_{2}$. Silica nanoparticles were visible on the fibers, creating a rough surface. The addition of $\mathrm{Ce}\left(\mathrm{NO}_{3}\right)_{3}$ resulted in reduction of the fiber diameter in comparison to the PAA/ $\mathrm{SiO}_{2}$ fiber (Table 2), which can be explained by the increase of charge density upon addition of the metal salt, inducing larger Coulombic interactions and, therefore, higher stretching of the electrospinning jet. ${ }^{45}$ After calcination at $600{ }^{\circ} \mathrm{C}$, the morphology of the fibers was preserved and the diameter of the fibers decreased owing to the removal of the polymer template. The incorporation of silica nanoparticles into the metal oxide fibers increased remarkably the surface area of the electrospun mats. The specific surface area of neat $\mathrm{CeO}_{2}$ fibers was $38 \mathrm{~m}^{2} \mathrm{~g}^{-1}$, whereas it increased to 161,155 , and $127 \mathrm{~m}^{2} \mathrm{~g}^{-1}$ for $\mathrm{SiO}_{2}, \mathrm{CeO}_{2} / \mathrm{SiO}_{2}(0.12 / 1.00)$, and $\mathrm{CeO}_{2} / \mathrm{SiO}_{2}(0.06 / 1.00)$, 

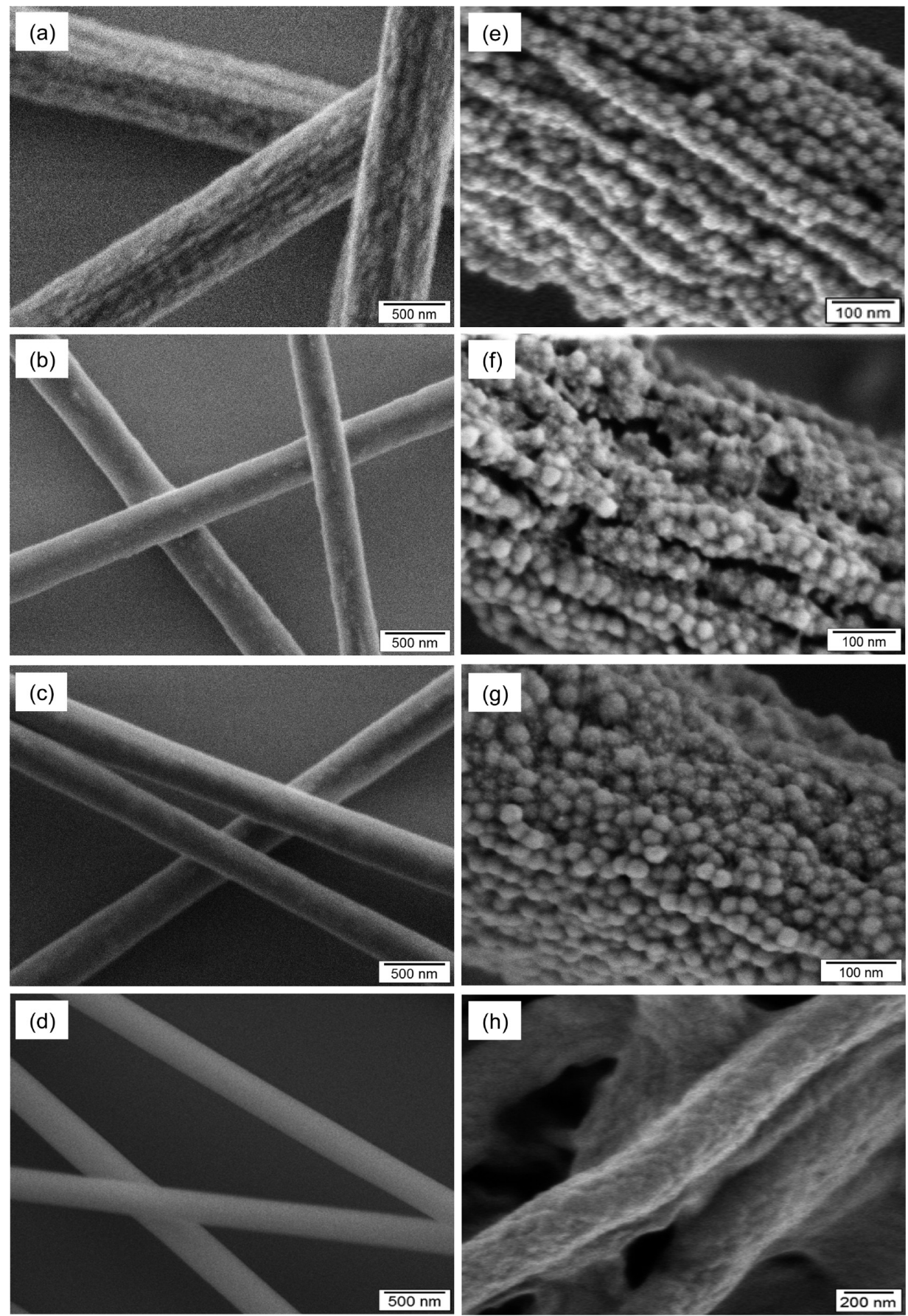

Figure 3. SEM micrographs of composite fibers as prepared: (a) $\mathrm{PAA} / \mathrm{SiO}_{2} ;(\mathrm{b}, \mathrm{c}) \mathrm{PAA} / \mathrm{Ce}\left(\mathrm{NO}_{3}\right)_{3} / \mathrm{SiO}_{2}$ with Ce/Si molar ratios of 0.06 and 0.12 , respectively, (d) $\mathrm{PAA} / \mathrm{Ce}\left(\mathrm{NO}_{3}\right)_{3}$; and oxide fibers after calcination at $600{ }^{\circ} \mathrm{C}$ : (e) $\mathrm{SiO}_{2}$, (f) $\mathrm{CeO}_{2} / \mathrm{SiO}_{2}(0.06 / 1.00),(\mathrm{g}) \mathrm{CeO} 2 / \mathrm{SiO}_{2}(0.12 / 1.00)$, (h) $\mathrm{CeO}_{2}$.

respectively. The hierarchy of size observed in the fibers (metal oxide crystallites < silica nanoparticles < fibers) is reflected in the hierarchy of porosity in the structure. Accordingly, there were two levels of porosity: the porosity created by the space between electrospun fibers, and the porosity of the silica particles, both contributing to the porosity of the resulting fibers.

The morphologies of the $\mathrm{LiCoO}_{2}$ and $\mathrm{LiCoO}_{2} / \mathrm{SiO}_{2}$ fibers are shown in Figure $4 a-c$. The PAA/LiOH/Co(OH) fibers before calcination were continuous, smooth, and uniform, with a diameter of $310 \pm 60 \mathrm{~nm}$. Similar to the $\mathrm{CeO}_{2}$ fibers, the calcination caused shrinkage of the average fiber diameter of
$\mathrm{LiCoO}_{2}$ to $190 \pm 30 \mathrm{~nm}$. $\mathrm{LiCoO}_{2} / \mathrm{SiO}_{2}$ fibers were clearly less brittle than neat $\mathrm{LiCoO}_{2}$ fibers. Whereas the $\mathrm{LiCoO}_{2}$ mat was converted to ultrafine pieces and powder (photograph on the top of Figure 1), the mat of $\mathrm{LiCoO}_{2} / \mathrm{SiO}_{2}$ (bottom image) remained intact after calcination. The nonwoven could be therefore handled as single object, which was not the case for the calcinated metal oxide fibers. We investigated the effect of calcination temperature on the fiber morphology. At $300{ }^{\circ} \mathrm{C}$, a phase separation was observed on the surface of fibers (Figure 4a). The components (i.e., polymer chains, residues, and metal oxide/salt) were separated into distinct domains oriented along the surface of the fibers. This phase separation occurred 

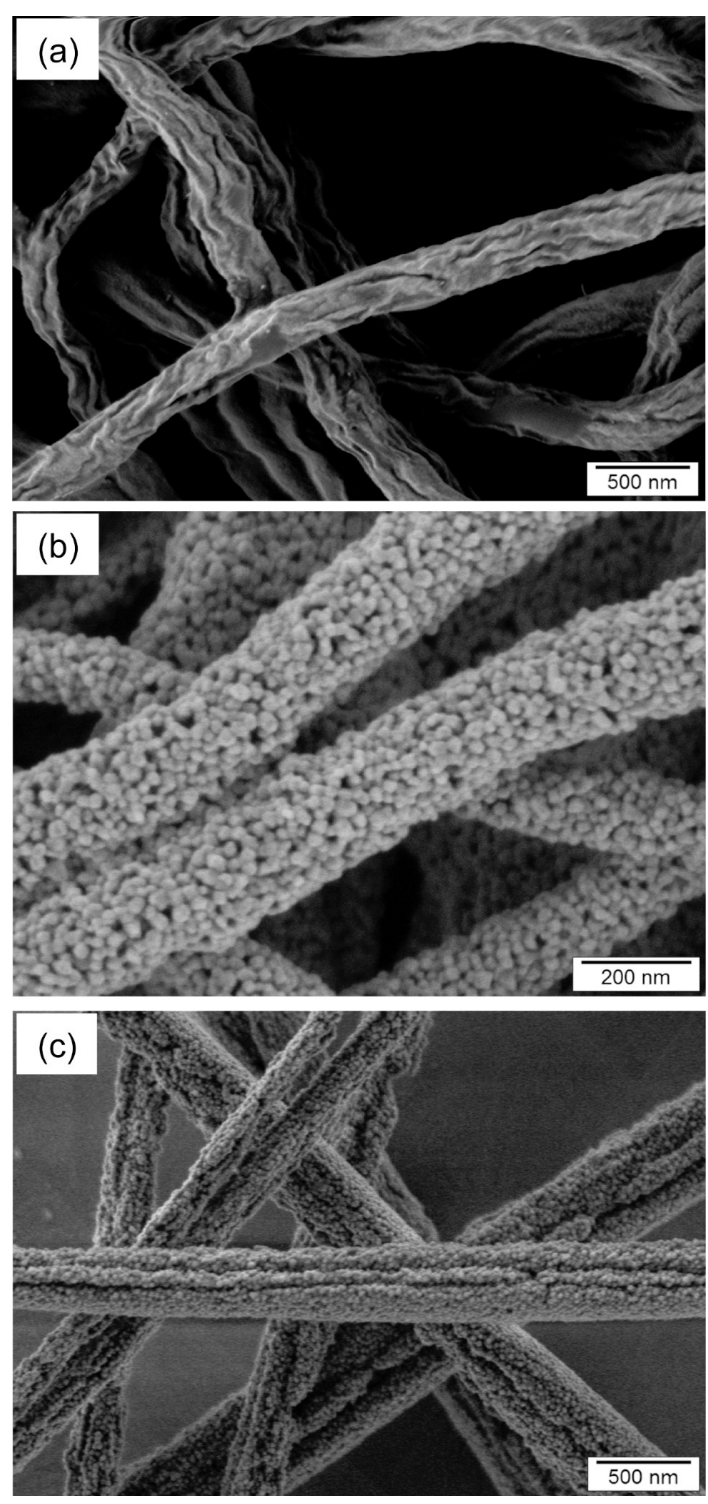

Figure 4. SEM micrographs of $\mathrm{PAA} / \mathrm{LiOH} / \mathrm{Co}(\mathrm{OH})_{2}$ precursor fibers after calcination (a) at $300{ }^{\circ} \mathrm{C}$, (b) at $400{ }^{\circ} \mathrm{C}$ and (c) PAA/LiOH/ $\mathrm{Co}(\mathrm{OH})_{2} / \mathrm{SiO}_{2}$ precursor fibers calcinated at $600{ }^{\circ} \mathrm{C}$.

uniformly on the surface along the long axis of the fiber wherein polymer-lean and polymer-rich phases were formed, indicating a spinodal decomposition. The orientation of the domains is probably a consequence of elongational electrical forces occurring during electrospinning process. When the calcination temperature was increased to $400{ }^{\circ} \mathrm{C}$, the fibers preserved their continuous structures and the average diameter was reduced by about $40 \%$ with narrower distribution $(25 \%)$. At the same time, the nucleation and growth of $\mathrm{LiCoO}_{2}$ nanoparticles occurred and the $\mathrm{LiCoO}_{2}$ nanoparticles were visible on the fibers surface (Figure 4b). The PAA aqueous solution composed of lithium/ cobalt hydroxides was basic $(\mathrm{pH} \sim 9)$. Under this condition, surface silanols are dissociated into negatively charged oxide $\left(\mathrm{Si}-\mathrm{O}^{-}\right)$on the surface. Electrostatic repulsion between negatively charged particles resulted in stable and nonaggregated silica dispersions. In the presence of silica nanoparticles of uniform size in the fibers, homogeneously assembled continuous fibers could be formed (Figure 4c).
The crystallinity of the samples was studied by X-ray diffraction (XRD). Figure 5a shows the XRD patterns of fibers
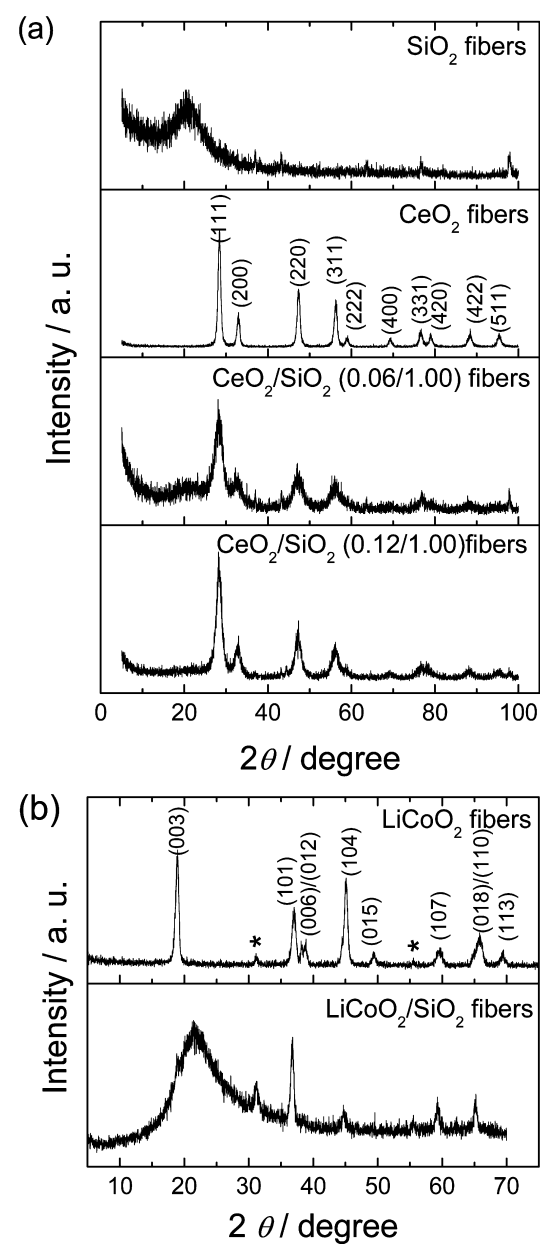

Figure 5. (a) $\mathrm{XRD}$ patterns of $\mathrm{SiO}_{2}$ fibers (blank) and $\mathrm{CeO}_{2}$ fibers prepared in the absence and presence of $\mathrm{SiO}_{2}$ nanoparticles after calcination at $600{ }^{\circ} \mathrm{C}$; (b) XRD patterns of lithium cobalt oxide fibers prepared in the absence and presence of $\mathrm{SiO}_{2}$ nanoparticles after calcination at $400{ }^{\circ} \mathrm{C}$ (the stars indicate reflections of $\mathrm{Co}_{3} \mathrm{O}_{4}$ ).

prepared with different $\mathrm{CeO}_{2} / \mathrm{SiO}_{2}$ ratios $(0.06 / 1.00$ and 0.12 / 1.00) after calcination at $600{ }^{\circ} \mathrm{C}$, compared with those of $\mathrm{SiO}_{2}$ and $\mathrm{CeO}_{2}$ fibers. Whereas the silica fibers displayed a typical amorphous halo, the samples containing cerium showed the characteristic reflections for cubic $\mathrm{CeO}_{2}$ (JCPDS card No. 34394). The increase of the amount of cerium salt resulted in sharper reflections, which correlates with the size of the crystalline domains. Under the same experimental conditions, $\mathrm{CeO}_{2}$ fibers prepared without colloid silica showed much narrower reflections. The sizes of the crystallites estimated by the Scherrer equation ${ }^{46}$ from the (111) reflection were 4,6 , and $12 \mathrm{~nm}$ for the $\mathrm{CeO}_{2} / \mathrm{SiO}_{2}(0.06 / 1.00), \mathrm{CeO}_{2} / \mathrm{SiO}_{2}(0.12 / 1.00)$ and $\mathrm{CeO}_{2}$ fibers, respectively. These results indicate that the size of the ceria crystallites was smaller in the presence of amorphous silica and increased with increasing amount of cerium. The change in the crystallite size can be associated with the interfacial area between the colloid and the ceria salt. Because colloidal silica provides large surface area, there may be higher number of nucleation sites compared to the fibers prepared in the absence of the colloids, so that the resulting crystallites are smaller. When the amount of cerium nitrate 
increased, while keeping constant the amount of the $\mathrm{SiO}_{2}$ nanoparticles, there was no change in nucleation sites and the diameter of the particles increased.

Figure $5 \mathrm{~b}$ contains the $\mathrm{XRD}$ patterns of the binary metal oxide fibers after calcination of $\mathrm{PAA} / \mathrm{LiOH} / \mathrm{Co}(\mathrm{OH})_{2}$ in the absence and in the presence of $\mathrm{SiO}_{2}$. In the absence of $\mathrm{SiO}_{2}$, the diffractogram confirms the formation of $\mathrm{LiCoO}_{2}$ (JCPDS card no. 44-0145), with a minor coexistence of $\mathrm{Co}_{3} \mathrm{O}_{4}$ (JCPDS card no. 42-1467). In the fibers formed in the presence of $\mathrm{SiO}_{2}$ nanoparticles, the $\mathrm{Co}_{3} \mathrm{O}_{4}$ phase becomes more significant, which may be ascribed to the formation of lithiated $\mathrm{Co}_{3} \mathrm{O}_{4}$ and/ or nonstoichimetric lithium cobalt oxide. The coexistence of $\mathrm{Co}_{3} \mathrm{O}_{4}$ and the formation of nonstoichiometric lithium cobalt oxides have been often reported in solid-state reaction methods from metal salts. ${ }^{47-49}$ A crystallite size of $14 \mathrm{~nm}$ was estimated by the Scherrer equation from the most intense (003) reflection for the $\mathrm{LiCoO}_{2}$ obtained without $\mathrm{SiO}_{2}$. The crystallite size is consistent with the particle size estimated statistically from SEM micrographs $(21 \pm 5 \mathrm{~nm}$, Figure $4 \mathrm{~b})$.

The backscattered electrons detection mode of the SEM was used to localize $\mathrm{LiCoO}_{2}$ nanoparticles among the $\mathrm{SiO}_{2}$ (Figure 6), thanks to the atomic number contrast between both type of
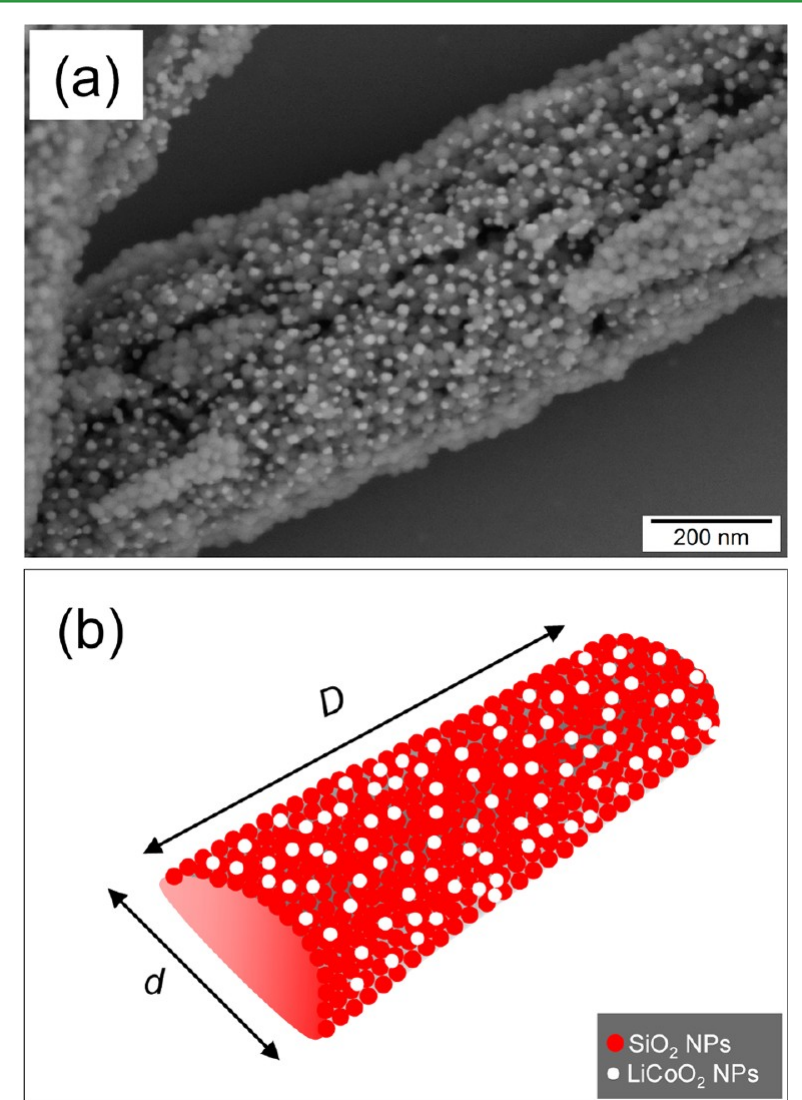

Figure 6. (a) SEM micrograph of a $\mathrm{LiCoO}_{2} / \mathrm{SiO}_{2}$ fiber obtained by calcination at $600{ }^{\circ} \mathrm{C}$ and (b) schematic representation of the simple geometrical model used to calculate percent volume of $\mathrm{LiCoO}_{2} / \mathrm{SiO}_{2}$ nanoparticles.

particles $\left(\mathrm{SiO}_{2}\right.$, and $\left.\mathrm{LiCoO}_{2}\right) \cdot \mathrm{LiCoO}_{2}$ nanoparticles with a diameter of $12 \pm 3 \mathrm{~nm}$ could be identified, being uniformly dispersed among the $\mathrm{SiO}_{2}$ particles in the fiber. The experimental and theoretical volume percents of the particles, $V_{\mathrm{MO}[\exp ]}$ and $V_{\mathrm{MO}[\mathrm{th}]}$, were calculated from statistical measurements of particles sizes in SEM images using eqs 1 and 2

$$
\begin{aligned}
& V_{\mathrm{MO}[\exp ]} \%=\frac{N V_{\mathrm{p}(\mathrm{MO})}}{A D_{\mathrm{SiO}_{2}}} \times 100 \\
& V_{\mathrm{MO}[\mathrm{th}]} \%=\frac{V_{\mathrm{MO}}}{V_{\mathrm{MO}}+V_{\mathrm{SiO}_{2}}} \times 100
\end{aligned}
$$

$N$ represents the number of $\mathrm{LiCoO}_{2}$ particles on the surface of a half cylinder $(A), D_{\mathrm{SiO}_{2}}$ the radius of the $\mathrm{SiO}_{2}$ nanoparticles, and $V_{\mathrm{p}}$ is the volume of one spherical $\mathrm{LiCoO}_{2}$ particle. The experimental volume percent was found to be $5.0 \%$, which was above the theoretical value of $4.4 \%$. Note that $V_{\mathrm{MO} \text { [exp] }}$ represents the volume of $\mathrm{LiCoO}_{2}$ that was observed by SEM, that is, located on the surface of the fibers. Therefore, the small difference between $V_{\mathrm{MO}[\exp ]}$ and $V_{\mathrm{MO}[\mathrm{th}]}$ suggests that the $\mathrm{LiCoO}_{2}$ nanoparticles are preferably situated at the fibers surface. Based in Figure 6a, we estimated that $18 \%$ of the total amount $\mathrm{LiCoO}_{2}$ nanoparticles were present on the surface of the fibers. The fact that the surface is enriched with the metal oxide is particularly remarkable, because the metal oxide is the functional component, whereas silica plays the role of a structural framework. Such nanocomposites have potential applications as cathodes of lithium-ion batteries, functional membranes for filtration, and supported catalysts.

As a representative example, the photocatalytic activity of the $\mathrm{CeO}_{2} / \mathrm{SiO}_{2}$ fibers for the degradation of rhodamine $\mathrm{B}$ was investigated and compared with the $\mathrm{SiO}_{2}$ fibers and the brittle $\mathrm{CeO}_{2}$ fibers. The evolution of the reaction was monitored by recording the photoluminescence $(\mathrm{PL})$ emission spectra of the samples at different times (Figure 7). The maximum at $580 \mathrm{~nm}$ decreased exponentially with respect to the irradiation time (Figure $7 \mathrm{~b}$ ). As expected, the decay of fluorescence intensity at time $t$ over initial intensity $\left(I / I_{0}\right)$ is slower for silica-supported fibers than for the neat fibers. The absolute performance of the fibers for the degradation of the dye, which is proportional to $P(\%)=100-\left(I / I_{0}\right)$, was found to increase from $P=10 \%$ $\left(\mathrm{CeO}_{2} / \mathrm{SiO}_{2}: 0.06 / 1.00\right)$ to $P=61 \%\left(\mathrm{CeO}_{2} / \mathrm{SiO}_{2}: 0.12 / 1.00\right)$ when the concentration of ceria in the fibers was increased. Although $P$ was found to be higher for the neat $\mathrm{CeO}_{2}$ fibers (66\%), the performance related to the amount of ceria in the fibers $P_{\text {w }}$ are much higher for the $\mathrm{CeO}_{2} / \mathrm{SiO}_{2}: 0.12 / 1.00(60 \%$ per $\mathrm{mg}$ of $\mathrm{CeO}_{2}$ ) than for the neat $\mathrm{CeO}_{2}$ fibers $(33 \%$ per $\mathrm{mg}$ ). This comparatively higher activity is explained by the fact that $\mathrm{CeO}_{2}$ was well-distributed along the fibers surface, being therefore accessible for the molecules to be degraded. This result is important because the efficient use of metal oxide allows the reduction of the production costs, taking into account that $\mathrm{SiO}_{2}$ is rather inexpensive and largely available as resource.

\section{CONCLUSIONS}

The simultaneous electrospinning of ceria and lithium cobalt oxide precursors and silica nanoparticles allows the fabrication of hierarchically structured composite nanofibers. The metal oxide was found to nucleate predominantly at the surface of the fibers during the calcination process, forming nanoparticles that were mainly present among larger silica nanoparticles on the surface of even larger fibers. This hierarchical structural organization enhanced the available surface area of the catalytically active metal oxide component and improved accordingly the efficiency of the system for catalysis, as shown by the successful degradation of a fluorescent dye by ceria fibers. Moreover, the presence of silica nanoparticles as 

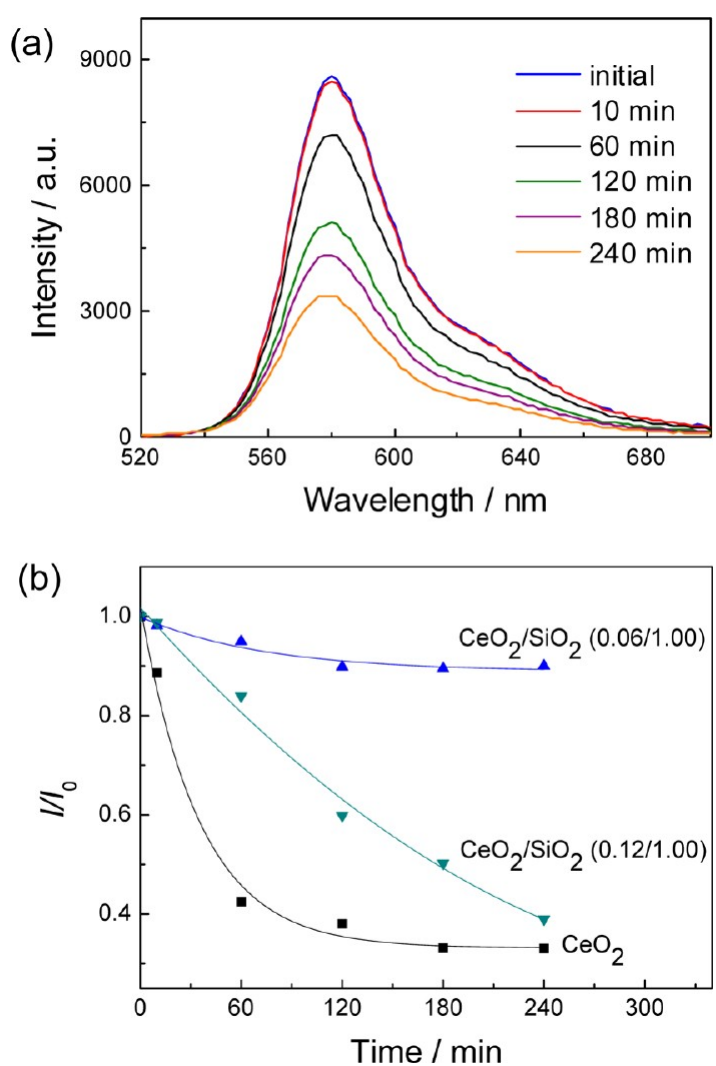

Figure 7. (a) PL emission spectra of rhodamine $\mathrm{B}$ solutions in the presence of $\mathrm{CeO}_{2} / \mathrm{SiO}_{2}(0.12 / 1.00)$ fibers at different time intervals, and (b) effect of different fiber catalysts on the photocatalytic degradation of rhodamine $\mathrm{B}$.

structural framework for the fibers improved both thermal and mechanical stability of the nanocomposites. The conjugation of the latter features with the functionality provided by the metal oxide and the versatility of the electrospinning technique make our method extendable to a large variety of supported metal oxides.

\section{AUTHOR INFORMATION}

\section{Corresponding Author}

*Fax: +49 6131 379-100. Tel: +49 6131 379-484. E-mail: crespy@mpip-mainz.mpg.de.

\section{Author Contributions}

The manuscript was written through contributions of all authors. All authors have given approval to the final version of the manuscript.

\section{Notes}

The authors declare no competing financial interest.

\section{ACKNOWLEDGMENTS}

The authors thank Michael Steiert for XRD measurements. The financial support by the International Max Planck Research School for Polymer Materials Science (IMPRS-PMS, Mainz) is gratefully acknowledged.

\section{REFERENCES}

(1) Choi, S. W.; Park, J. Y.; Kim, S. S. Nanotechnology 2009, 20, 1-6.

(2) Fierro, J. L. G. In Metal Oxides: Chemistry and Applications, 1st

ed.; Taylor and Francis: Boca Raton, FL, 2006; Vol. 2, p 32.

(3) Kim, I. D.; Rothschild, A. Polym. Adv. Technol. 2011, 22, 318325.
(4) Valcarcel, V.; Souto, A.; Guitian, F. Adv. Mater. 1998, 10, 138140.

(5) Chen, B. J.; Sun, X. W.; Xu, C. X.; Tay, B. K. Phys. E 2004, 21, $103-107$.

(6) Yoo, S.; Dregia, S. A.; Akbar, S. A. J. Mater. Res. 2006, 21, 18221829.

(7) Li, D.; Wang, Y. L.; Xia, Y. N. Nano Lett. 2003, 3, 1167-1171.

(8) Huang, Z. M.; Zhang, Y. Z.; Kotaki, M.; Ramakrishna, S. Compos. Sci. Technol. 2003, 63, 2223-2253.

(9) Sigmund, W.; Yuh, J.; Park, H.; Maneeratana, V.; Pyrgiotakis, G.; Daga, A.; Taylor, J.; Nino, J. C. J. Am. Ceram. Soc. 2006, 89, 395-407.

(10) Fridrikh, S. V.; Yu, J. H.; Brenner, M. P.; Rutledge, G. C. Phys. Rev. Lett. 2003, 90, 144502-144501-144504.

(11) Theron, S. A.; Zussman, E.; Yarin, A. L. Polymer 2004, 45, 2017-2030.

(12) Choi, S. S.; Lee, S. G.; Im, S. S.; Kim, S. H.; Joo, Y. L. J. Mater. Sci. Lett. 2003, 22, 891-893.

(13) Hansen, N. S.; Ferguson, T. E.; Panels, J. E.; Park, A. H. A.; Joo, Y. L. Nanotechnology 2011, 22, 1-13.

(14) Ma, Z. J.; Ji, H. J.; Teng, Y.; Dong, G. P.; Zhou, J. J.; Tan, D. Z.; Qiu, J. R. J. Colloid Interface Sci. 2011, 358, 547-553.

(15) Panels, J. E.; Joo, Y. L. J. Nanomater. 2006, 2006, 1-10.

(16) Sakai, S.; Yamada, Y.; Yamaguchi, T.; Kawakami, K. Biotechnol. J. 2006, 1, 958-962.

(17) Sakai, S.; Yamaguchi, T.; Putra, R. A.; Watanabe, R.; Kawabe, M.; Taya, M.; Kawakami, K. J. Sol-Gel Sci. Technol. 2012, 61, 374380.

(18) Seol, Y. J.; Kim, K. H.; Kang, Y. M.; Kim, I. A.; Rhee, S. H. J. Biomed. Mater. Res., Part B 2009, 90B, 679-687.

(19) Ding, B.; Kim, H.; Kim, C.; Khil, M.; Park, S. Nanotechnology 2003, 14, 532-537.

(20) Kim, Y. J.; Ahn, C. H.; Choi, M. O. Eur. Polym. J. 2010, 46, $1957-1965$

(21) Shao, C. L.; Kim, H.; Gong, J.; Lee, D. Nanotechnology 2002, 13, 635-637.

(22) Shi, W.; Lu, W. S.; Jiang, L. J. Colloid Interface Sci. 2009, 340, 291-297.

(23) Chen, Y. Z.; Zhang, Z. P.; Yu, J.; Guo, Z. X. J. Polym. Sci., Part B: Polym. Phys. 2009, 47, 1211-1218.

(24) Friedemann, K.; Corrales, T.; Kappl, M.; Landfester, K.; Crespy, D. Small 2012, 8, 144-153.

(25) Kanehata, M.; Ding, B.; Shiratori, S. Nanotechnology 2007, 18, $1-7$.

(26) Lim, J. M.; Moon, J. H.; Yi, G. Y.; Heo, C. J.; Yang, S. M. Langmuir 2006, 22, 3445-3449.

(27) Zhang, X. C.; Chen, Y. Z.; Yu, J.; Guo, Z. X. J. Polym. Sci., Part B: Polym. Phys. 2011, 49, 1683-1689.

(28) Li, L.; Meyer, W. H.; Wegner, G.; Wohlfahrt-Mehrens, M. Adv. Mater. 2005, 17, 984-988.

(29) Lu, G. Q.; Lieberwirth, I.; Wegner, G. J. Am. Chem. Soc. 2006, $128,15445-15450$.

(30) Horzum, N.; Tascioglu, D.; Okur, S.; Demir, M. M. Talanta 2011, 85, 1105-1111.

(31) Crespy, D.; Friedemann, K.; Popa, A. M. Macromol. Rapid Commun. 2012, DOI: 10.1002/marc.201200549.

(32) Wesselt, C.; Ostermann, R.; Dersch, R.; Smarsly, B. M. J. Phys. Chem. C 2011, 115, 362-372.

(33) Kanjwal, M. A.; Barakat, N. A. M.; Sheikh, F. A.; Park, S. J.; Kim, H. Y. Macromol. Res. 2010, 18, 233-240.

(34) Kanjwal, M. A.; Sheikh, F. A.; Barakat, N. A. M.; Chronakis, I. S.; Kim, H. Y. Appl. Surf. Sci. 2011, 257, 7975-7981.

(35) Kanjwal, M. A.; Sheikh, F. A.; Barakat, N. A. M.; Li, X. Q.; Kim, H. Y.; Chronakis, I. S. Appl. Surf. Sci. 2012, 258, 3695-3702.

(36) Strunk, J.; Vining, W. C.; Bell, A. T. J. Phys. Chem. C 2011, 115, 4114-4126.

(37) Tang, C. J.; Zhang, H. L.; Sun, C. Z.; Li, J. C.; Qi, L.; Quan, Y. J.; Gao, F.; Dong, L. Catal. Commun. 2011, 12, 1075-1078.

(38) Zhao, X. B.; Long, R. W.; Chen, Y.; Chen, Z. G. Microelectron. Eng. 2010, 87, 1716-1720. 
(39) Pradip; Maltesh, C.; Somasundaran, P.; Kulkarni, R. A.; Gundiah, S. Langmuir 1991, 7, 2108-2111.

(40) Moharram, M. A.; Khafagi, M. G. J. Appl. Polym. Sci. 2006, 102, $4049-4057$.

(41) Shih, S. J.; Borisenko, K. B.; Liu, L. J.; Chen, C. Y. J. Nanopart. Res. 2010, 12, 1553-1559.

(42) Mahmoud, W. E.; Al-Agel, F. A. J. Phys. Chem. Solids 2011, 72, 904-907.

(43) Carewska, M.; Di Bartolomeo, A.; Scaccia, S. Thermochim. Acta 1995, 269-270, 491-506.

(44) Mizuno, Y.; Hosono, E.; Saito, T.; Okubo, M.; Nishio-Hamane, D.; Oh-ishi, K.; Kudo, T.; Zhou, H. J. Phys. Chem. C 2012, 116, 10774-10780.

(45) Zong, X. H.; Kim, K.; Fang, D. F.; Ran, S. F.; Hsiao, B. S.; Chu, B. Polymer 2002, 43, 4403-4412.

(46) Langford, J. I.; Wilson, A. J. C. J. Appl. Crystallogr. 1978, 11, $102-113$.

(47) Antolini, E. Mater. Res. Bull. 1997, 32, 9-14.

(48) Antolini, E. Solid State Ionics 2004, 170, 159-171.

(49) Rossen, E.; Reimers, J. N.; Dahn, J. R. Solid State Ionics 1993, 62, $53-60$. 